\title{
Article \\ Spherical Fuzzy Multicriteria Decision-Making Model for Wind Turbine Supplier Selection in a Renewable Energy Project
}

\author{
Van Thanh Nguyen ${ }^{1}$, Nguyen Hoang Hai ${ }^{1, *}$ and Nguyen Thi Kim Lan ${ }^{2}$ \\ 1 Faculty of Commerce, Van Lang University, Ho Chi Minh City 70000, Vietnam; thanh.nguyenvan@vlu.edu.vn \\ 2 International Education Institute, Van Lang University, Ho Chi Minh City 70000, Vietnam; lan.ntk@vlu.edu.vn \\ * Correspondence: hai.nh@vlu.edu.vn
}

\section{check for} updates

Citation: Nguyen, V.T.; Hai, N.H.; Lan, N.T.K. Spherical Fuzzy Multicriteria Decision-Making Model for Wind Turbine Supplier Selection in a Renewable Energy Project. Energies 2022, 15, 713. https:// doi.org/10.3390/en15030713

Academic Editor: José A.F.O. Correia

Received: 14 December 2021

Accepted: 17 January 2022

Published: 19 January 2022

Publisher's Note: MDPI stays neutral with regard to jurisdictional claims in published maps and institutional affiliations.

Copyright: (C) 2022 by the authors. Licensee MDPI, Basel, Switzerland. This article is an open access article distributed under the terms and conditions of the Creative Commons Attribution (CC BY) license (https:// creativecommons.org/licenses/by/ $4.0 /)$.

\begin{abstract}
The Vietnamese government has decided to use and promote the development of more renewable energy sources, particularly wind energy. When implementing a wind energy project, choosing a wind turbine supplier is an important decision and investors must find the optimal supplier through evaluating many qualitative and quantitative criteria that affect each other symmetrically. Therefore, the process used for selecting a wind turbine supplier in wind power projects is a multi-criteria decision-making process. Many approaches have been applied for this decision process, some of which are based on multicriteria decision-making (MCDM) methods, whether applied individually or in combination with other MCDM models. In this study, the researchers proposed a decision-making model based on spherical fuzzy sets for wind turbine supplier selection in wind power energy projects. In this paper, Vietnam is used as a case study. The recommended turbine suppliers for installations can finally be generated after the calculations in the final stage of this research. The contribution of this research is developing a fuzzy MCDM model for suitable turbine suppliers in wind power energy projects. The results of this study can be used as references for experts in deciding on a suitable wind turbine supplier in other countries as well as in other renewable energy projects.
\end{abstract}

Keywords: fuzzy theory; MCDM model; spherical fuzzy sets; wind turbine supplier selection; renewable energy

\section{Introduction}

With more than $3200 \mathrm{~km}$ of coastline and a total marine area of about 1 million $\mathrm{km}^{2}$, Vietnam has huge potential for investment in offshore wind energy projects. The annual average wind speed at an altitude of $100 \mathrm{~m}$ can reach 9-10 m/s in many sea areas of Vietnam. Only in the sea areas around Phu Quy or Bach Long Vi islands does the potential installed capacity reach up to $38 \mathrm{GW}$ [1]. With a resource potential amongst the highest in the world and a rapidly increasing electricity demand, Vietnam is poised to become a leader in offshore wind power in Southeast Asia within the next decade.

Wind energy, along with other clean energy sources, is widely applied. Environmental pollution is becoming an increasingly serious problem. One of the best ways to reduce emissions into the environment and lower pollution is to use clean energy [2]. Developing wind energy is a high priority of the Vietnamese government.

Wind energy can be described as the process by which natural wind is absorbed and transformed to generate mechanical energy, or electrical energy, for daily usage. To exploit wind energy, we need to deploy and install wind turbines [3]. Modern wind turbines are divided into two types: horizontally orientated wind turbines and vertically orientated wind turbines. Conventional horizontal axis wind turbines usually have two or three blades. Wind turbines have three blades that operate on a vertical wind mechanism, and these blades face the wind directly. Wind turbines can be built on land or near the coast in aquatic areas-e.g., the ocean or large reservoirs [4]. Thus, an important component 
of wind energy projects is the wind turbine itself. Currently, there are many suppliers of wind turbines. Deciding on a suitable supplier has great influence on the completion time and operational efficiency of wind energy projects. Thus, this is a complex decision that requires the consideration of multiple factors.

The selection of a wind turbine supplier in wind power energy projects is a multicriteria decision-making process. MCDM methodologies are best describedas methods used for making decisions when multiple criteria (or objectives) need to be considered together in order to determine an overall ranking of the options $[5,6]$.

The authors of this study propose an MCDM model based on spherical fuzzy sets for wind turbine supplier selection in wind power energy projects. After determining the evaluation criteria and options, two MCDM methods, Spherical Fuzzy Analytic Hierarchy Process (SF-AHP) and Weighted Aggregated Sum Product Assessment (WASPAS), were used in this study in the final evaluation and selection of a wind turbine supplier. Finally, an application is presented to demonstrate the potential use of the proposed methodology.

\section{Literature Review}

Decision analysis is an important tool for solving issues that involve multiple actors, criteria, and objectives. Hsing Chen Lee et al. [7] used MCDM models for ranking renewable energy sources. In this research, the authors used four MCDM models: WSM, VIKOR, TOPSIS, and ELECTRE. The results of this research can provide valuable information to energy decision makers and act as a reference for Taiwan's power policy. Abhishek Kumar et al. [8] also provide insight into various MCDM techniques for renewable energy applications.

Murat Çolak et al. [9] integrated fuzzy MCDM models for the prioritization renewable energy options. In their work, the authors applied an analytic hierarchy process (AHP) based on interval type-2 fuzzy sets and persistent fuzzy TOPSIS methodologies. Arash Sadeghi et al. [10] utilized a fuzzy MCDM model to evaluate four alternative renewable energies: solar energy, geothermal energy, hydropower energy, and wind energy. The authors used fuzzy AHP and fuzzy TOPSIS for ranking the four options in their research.

Tien-Chin Wang et al. [11] applied a fuzzy MCDM model including fuzzy FAHP and data envelopment analysis (DEA) to determine a solar panel supplier for a solar power energy project in Taiwan. The results of this study presented a new fuzzy MCDM method for supplier selection in an unclear and uncertain environment. Sarmad Ishfaq et al. [12] discussed three important MCDM models: AHP, TOPSIS, and the VlseKriterijumska Optimizacija I Kompromisno Resenje (VIKOR). All three methods were utilized in the selection process for the best renewable energy options for Pakistan. Gülçin Büyüközkan et al. [13] implemented hesitant fuzzy linguistic term sets (HFLTS) to effectively evaluate a renewable energy sources strategy problem.

S. K. Saraswat et al. [14] applied Geographical Information System (GIS) and MCDM approaches for the assessment of solar and wind farm locations in India. Their findings can be used for the growth of policies related to renewable energies and the evaluation of the suitability of already-planned projects. Yunna Wu et al. [15] proposed a fuzzy MCDM model based on cumulative prospects to determine the suitability of renewable power sources. This study provided valuable findings for deciding the most suitable renewable power source, under unclear criteria, by giving public risk-taking investors different options. Mohsen Ramezanzade et al. [16] presented a hybrid fuzzy MCDM model in which VIKOR, distance from the average solution, and additive ratio assessment methods are used to rank renewable energy projects in a fuzzy environment.

Lee et al. [17] proposed an MCDM model which combines interpretive structural modeling (ISM) and a fuzzy analytic network process (FANP) to select suitable turbines when building a wind farm. The most appropriate turbines for installation can be determined after the calculations. The results can be shown to decision makers when determining the most suitable wind turbines. Nansheng Pang et al. [18] constructed a model for wind turbine unit determination by fuzzy preference programming (FPP) with an analytic network 
process (ANP). The results showed that the $2.5 \mathrm{~W}$ unit produced by Goldwind would give the best evaluation value, which is aligned with the expanding market share of permanent magnet direct-drive wind turbines. Meng Shao et al. [19] reviewed MCDM applications for renewable energy site selection. The authors focused on two types of criteria and methods in the five site selection stages. The results show that hybrid GISs and MCDMs are the most popular tools in this research area. Yunna $\mathrm{Wu}$ et al. [20] extended fuzzy TODIM-based two-stage decision-making frameworks for the optimal location selection of offshore windPV-seawater pumped storage power plants. Francisco G. Montoya et al. [21]. demonstrated the power of the application of multi-objective evolutionary algorithms (MOEAs) to wind turbine selection problems (WTS).

As this literature review shows, MCDM is a minor deviation from operational research dealing with determining optimal results in complex situations including various indexes, conflicting objectives, and multiple criteria. This popular tool in the field of energy planning is receiving attention due to the flexibility it provides for decision makers in finalizing decisions while considering all the criteria. However, there are very few studies using MCDM based on spherical fuzzy sets to develop a decision support system in wind power energy projects that supports project managers in evaluating and selecting optimal solutions. Thus, we propose a fuzzy MCDM model for wind turbine supplier selection in this research.

\section{Methodology}

\subsection{Research Graph}

The Fuzzy MCDM procedure creates an optimal supplier selection model, as shown in the steps and diagram (see Figure 1 below).

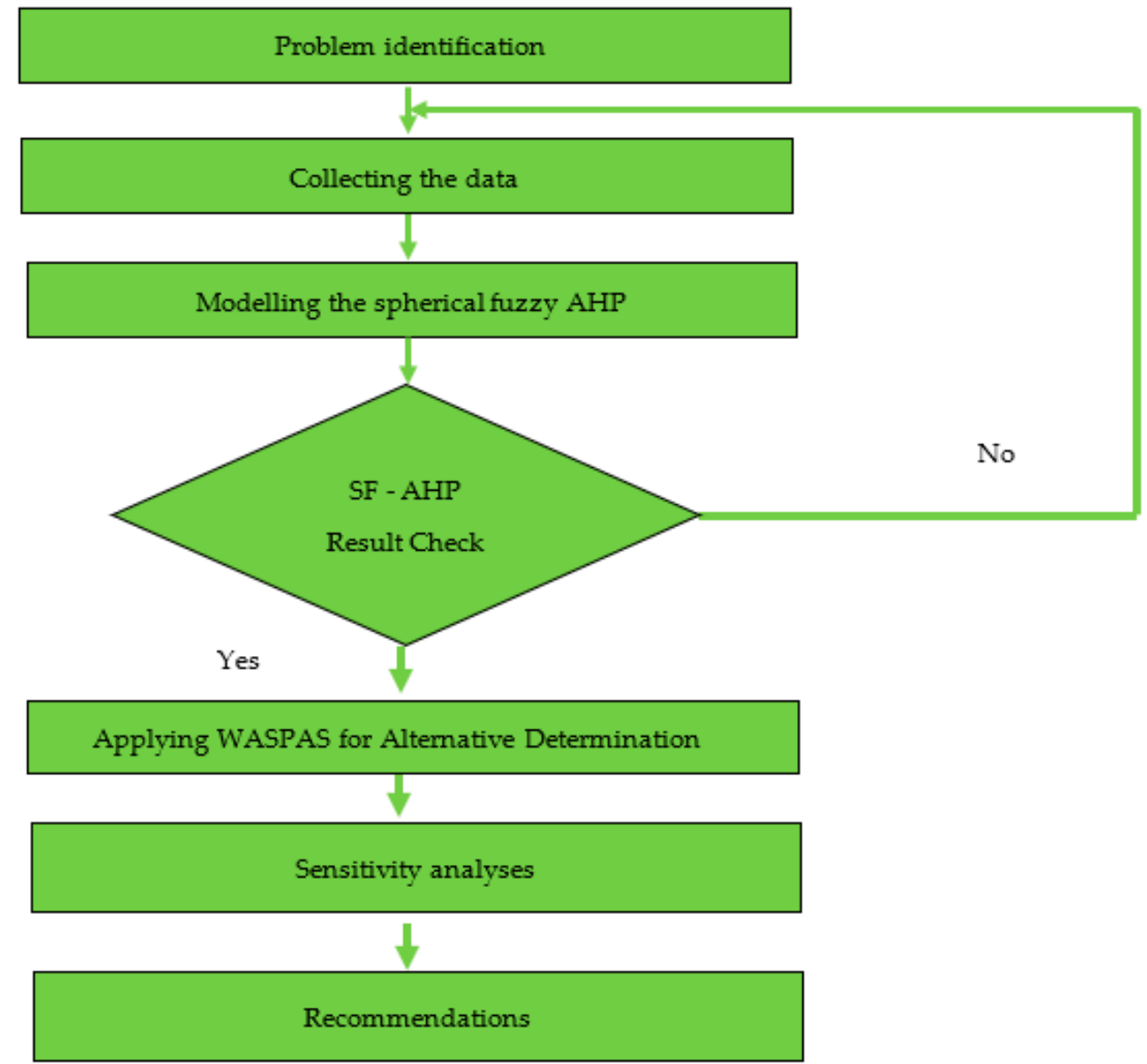

Figure 1. Research Graph. 
Step 1: Problem identification

Firstly, the sets of criteria that are influential in wind turbine supplier selection are defined by experts and when reviewing the literature.

Step 2: Apply spherical fuzzy AHP

The individual criteria weightings in the second evaluation stage are determined by the spherical fuzzy AHP model.

Step 3: Applying WASPAS for Alternative Determination

The WASPAS method is the weighted sum model (WSM) and the weighted product model (WPM) combined. Thus, the WASPAS model is applied for ranking all turbine suppliers listed in this stage.

\subsection{Theory of Spherical Fuzzy Sets}

Gundogdu et al. recently developed the spherical fuzzy sets theory as a fusion of Pythagorean fuzzy sets [22] and Neutrosophic sets [23]. The theory was developed based on the notion that a decision maker's hesitancy can be defined independently of related and non-related degrees, as well as the idea that a decision maker can generalize other extensions of fuzzy sets by determining a relationship function on a spherical platform [24].

The universe of $U_{1}$ spherical fuzzy sets $\widetilde{A}_{S}$ is defined as follows:

$$
\widetilde{A}_{S}=\left\{x,\left(\mu_{\widetilde{A}_{S}}(x), v_{\widetilde{A}_{S}}(x), \pi_{\widetilde{A}_{S}}(x) \mid x \in U_{1}\right\}\right.
$$

where:

$$
\mu_{\widetilde{A}_{S}}(x): U_{1} \rightarrow[0,1], v_{\widetilde{A}_{S}}(x): U_{1} \rightarrow[0,1] \text {, and } \pi_{\widetilde{A}_{S}}(x): U_{1} \rightarrow[0,1]
$$

and:

$$
0 \leq \mu_{\widetilde{A}_{S}}^{2}(x)+v_{\widetilde{A}_{S}}^{2}(x)+\pi_{\widetilde{A}_{S}}^{2}(x) \leq 1 \text { with } \forall x \in U_{1}
$$

The degree of membership is mu $\mu_{\widetilde{A}_{S}}(x)$, the degree of non-membership is $v_{\widetilde{A}_{S}}(x)$, and the hesitancy of $x$ to $\widetilde{A}_{S}$ is $\pi_{\widetilde{A}_{S}}(x)$.

In this way, Gundogdu and Kahraman [24] define and show the traditional arithmetic operations of spherical fuzzy sets.

\subsection{Model of the Spherical Fuzzy Analytic Hierarchy Process (SF-AHP)}

Gundogdu and Kahraman [24] created the SF-AHP approach, which is an extension of AHP that also uses spherical fuzzy sets. SF-AHP is used in this work to determine the weight of the individual selection criteria. Gundogdu and Kahraman's SF-AHP approach consists of 5 stages [24]:

Stage 1: Create a hierarchical structure for the model.

A three-tiered hierarchical framework is built. The model's aim, based on a score index, is to achieve Level 1. Level 2 of the structure determines the score index based on a set of $n$ criteria. Level 3 defines a collection of $m$ alternatives for $A$, where $m \geq 2$.

Stage 2: Create suitable direct comparison matrices for the criterion using spherical fuzzy decisions according to Gundogdu and Kahraman's [24] language terms as shown in Table 1.

The indices of scores (SI) for each option are calculated using Equations (3) and (4).

$$
S I=\sqrt{\left|100 *\left[\left(\mu_{\widetilde{A}_{s}}-\pi_{\widetilde{A}_{s}}\right)^{2}-\left(v_{\widetilde{A}_{s}}-\pi_{\widetilde{A}_{s}}\right)^{2}\right]\right|}
$$

These apply to the options of absolute highest importance, very high importance, high importance, slightly more importance, and equal importance. 
Table 1. Linguistic lexicons of importance [24].

\begin{tabular}{lcc}
\hline & $(\mu, v, \pi)$ & Score Index \\
\hline Aabsolute highest importance (AH) & $(0.9,0.1,0.0)$ & 9 \\
Very high importance (VH) & $(0.8,0.2,0.1)$ & 7 \\
High importance (HI) & $(0.7,0.3,0.2)$ & 5 \\
Slightly more importance (SM) & $(0.6,0.4,0.3)$ & 3 \\
Equally importance (EI) & $(0.5,0.4,0.4)$ & 1 \\
(SL) & $(0.4,0.6,0.3)$ & $1 / 3$ \\
Low importance (LI) & $(0.3,0.7,0.2)$ & $1 / 5$ \\
Very low importance (VL) & $(0.2,0.8,0.1)$ & $1 / 7$ \\
Absolutely lowest importance (AL) & $(0.1,0.9,0.0)$ & $1 / 9$ \\
\hline
\end{tabular}

$$
\frac{1}{S I}=\frac{1}{\sqrt{\left|100 *\left[\left(\mu_{\widetilde{A}_{s}}-\pi_{\widetilde{A}_{s}}\right)^{2}-\left(v_{\widetilde{A}_{s}}-\pi_{\widetilde{A}_{s}}\right)^{2}\right]\right|}}
$$

These apply to the options of slightly lower importance, low importance, very low importance, and absolutely lowest importance.

Stage 3: Examine each pairwise comparison matrix for consistency. The linguistic words in the pairwise comparison matrices are translated to the score indices that correspond to them. Then, we use the traditional consistency check with a $C R$ threshold of $10 \%$ :

$$
C R=\frac{C I}{R I}
$$

The Consistency Index $(C I)$ is computed as follows:

$$
C I=\frac{\lambda_{\max }-n}{n-1}
$$

where $\lambda_{\text {max }}$ is the matrix's maximum value and $n$ is the number of criteria.

The Random Index $(R I)$ is calculated using a variety of criteria [25].

Stage 4: Calculate the spherical fuzzy weights of the criteria and options.

The following equation is used to calculate the weight of each choice in relation to each criterion:

$$
\begin{aligned}
\operatorname{SWM}_{w}\left(A_{S 1}, \ldots, A_{S n}\right) & =w_{1} A_{S 1}+\ldots+w_{n} A_{S n} \\
= & \left\langle\left[1-\prod_{i=1}^{n}\left(1-\mu_{A_{S i}}^{2}\right)^{w_{i}}\right]^{1 / 2}, \prod_{i=1}^{n} V_{A_{S i}}^{w_{i}}\left[\prod_{i=1}^{n}\left(1-\mu_{A_{S i}}^{2}\right)^{w_{i}}-\prod_{i=1}^{n}\left(1-\mu_{A_{S i}}^{2}-\pi_{A_{S i}}^{2}\right)^{w_{i}}\right]^{1 / 2}\right\rangle
\end{aligned}
$$

where $w=1 / n$.

Stage 5: Using ascending layer sequencing, calculate the overall weights.

By modifying the spherical weights at each level of the ascending structure, the ultimate ranking of the options can be computed. At this point, there are two viable options for carrying out the computation.

The first method is to de-fuzzify the criterion weights using the score function in Equation (8):

$$
\left(\widetilde{w}_{j}^{S}\right)=\sqrt{\left|100 *\left[\left(3 \mu_{\widetilde{A}_{s}}-\frac{\pi_{\widetilde{A}_{s}}}{2}\right)^{2}-\left(\frac{v_{\widetilde{A}_{s}}}{2}-\pi_{\widetilde{A}_{s}}\right)^{2}\right]\right|}
$$


The criteria weights are then normalized using Equation (9) and spherical fuzzy multiplication is used in Equation (10):

$$
\begin{gathered}
\bar{w}_{j}^{s}=\frac{S\left(\widetilde{w}_{j}^{s}\right)}{\sum_{j=1}^{n} S\left(\widetilde{w}_{j}^{s}\right)} \\
\widetilde{A}_{S_{i j}}=\bar{w}_{j}^{s} * \widetilde{A}_{S_{i}}=\left\langle\left(1-\left(1-\mu_{\widetilde{A}_{S}}^{2}\right)^{\bar{w}_{j}^{s}}\right)^{1 / 2}, v_{\widetilde{A}_{S}^{s}}^{\bar{A}_{S}^{s}}\left(\left(1-\mu_{\widetilde{A}_{S}}^{2}\right)^{\bar{w}_{j}^{s}}-\left(1-\mu_{\widetilde{A}_{S}}^{2}-\pi_{\widetilde{A}_{S}}^{2}\right)^{\bar{w}_{j}^{s}}\right)^{1 / 2}\right\rangle
\end{gathered}
$$

with $\forall i$.

Equation (11) is used to determine the final ranking score $(\widetilde{F})$ for each option $A_{i}$ :

$$
\widetilde{F}=\sum_{j=1}^{n} \widetilde{A}_{S_{i j}}=\widetilde{A}_{S_{i 1}}+\widetilde{A}_{S_{i 2}}+\ldots+\widetilde{A}_{S_{i n}}
$$

The second option is to continue the calculation without de-fuzzifying the criterion weights. The spherical fuzzy global weights are computed as follows:

$$
\prod_{j=1}^{n} \widetilde{A}_{S_{i j}}=\widetilde{A}_{S_{i 1}} * \widetilde{A}_{S_{i 2}} * \ldots * \widetilde{A}_{S_{i n}}
$$

The conclusive decision value of each option is then computed using Equation (11).

\subsection{WASPAS Method}

The WSM approach is incredibly basic, easy to apply, and simple to comprehend. It computes an alternative's overall score as the weighted sum of the attribute values. This is the most well-known and commonly utilized approach [26]. WPM was created to prevent options with low attribute values. It computes the score of each choice as a product of the scale rating of each attribute's strengths multiplied by the importance weight of that attribute [27].

The WASPAS method's computational technique may be clearly described as follows:

Stage 1: The choice matrix is normalized.

The strategy of normalizing the decision matrix for the WASPAS approach is dependent on whether the choice criteria are advantageous or not. Normalization of the decision matrix, for the beneficial choice criterion, is accomplished as seen in Equation (13):

$$
q_{i j}=\frac{x_{i j}}{\max x_{i j}}, i=1,2, \ldots, n ; j=1,2, \ldots, m
$$

As demonstrated in Equation (14) for non-beneficial choice criteria:

$$
q_{i j}=\frac{x_{i j}}{\min x_{i j}}, i=1,2, \ldots, n ; j=1,2, \ldots, m
$$

Stage 2: Based on the WSM technique, compute the relative significance of the $i$ th choice as follows:

$$
S_{i}^{1}=\sum_{j=1}^{n} q_{i j} \times w_{j}
$$

Stage 3: WPM evaluates the performance index of the $i$ th alternative, as shown in Equation (16):

$$
S_{i}^{2}=\prod_{j=1}^{n}\left(q_{i j}\right)^{w_{j}}
$$

Stage 4: Using Equations (15) and (16), we design a WASPAS model to determine the total relative significance. The relative importance sum, or, more accurately, the general 
criterion of the weighted synthesis of the addition and multiplication processes, is as follows:

$$
F=\lambda S_{i}^{1}+(1-\lambda) S_{i}^{2}=\lambda \sum_{j=1}^{n} q_{i j} \times w_{j}+(1-\lambda) \prod_{j=1}^{n}\left(q_{i j}\right)^{w_{j}}
$$

where $\lambda$ is the coefficient and $\lambda \in[0,1]$. When there is no choice for the coefficient, its value is set to $\lambda=0.5$.

The options are rated based on a performance index, with the best option receiving the most weight.

\section{Case Study}

There are favorable factors in the Vietnam market for wind power investors to find great opportunities. Besides its natural potential, the Government is also showing strong support for wind power development and subsidizes wind power projects to reduce financial risk, allowing investors to test and set up new operations. According to wind energy survey data from the German Agency for International Cooperation (GIZ), the Mekong Delta region has wind potential that is easy to exploit and convenient for investors $[28,29]$. Therefore, there are many wind energy projects already underway in this area.

In this research, the author has proposed an MCDM based on spherical fuzzy sets for wind turbine supplier selection in wind power energy projects. All criteria are used for assessing wind turbine suppliers and are defined by 15 Experts (wind turbine mechanical engineers, renewable energy scientist, etc ... .) and the literature review, shown in Table 2 and Figure 2.

Table 2. Criteria used for supplier selection.

\begin{tabular}{|c|c|c|c|}
\hline Criteria & Subcriteria & Researchers & Expert Opinions \\
\hline \multirow[t]{3}{*}{ Machine Feature (MF) } & $\begin{array}{l}\text { Operations of wind turbine and Power } \\
\text { Ratio (MF1) }\end{array}$ & $\begin{array}{l}\text { Amy H.I.Lee et al. [17], } \\
\text { A. Ayca Supciller et al. [30] } \\
\text { Abdel-Monem et al. [31] }\end{array}$ & $x$ \\
\hline & Available of maintenance (MF2) & & $x$ \\
\hline & Turbine efficiency and Turbine speed (MF3) & $\begin{array}{l}\text { A. Ayca Supciller et al. [30], } \\
\text { Abdel-Monem et al. [31] }\end{array}$ & $x$ \\
\hline \multirow[t]{3}{*}{ Environmental (EN) } & Area use (EN1) & $\begin{array}{l}\text { Amy H.I.Lee et al. [17], } \\
\text { A. Ayca Supciller et al. [30] } \\
\text { Abdel-Monem et al. [31] }\end{array}$ & $x$ \\
\hline & Environmental impact (EN2) & Abdel-Monem et al. [31] & $X$ \\
\hline & Fuss/air and water pollution (EN3) & $\begin{array}{l}\text { A. Ayca Supciller et al. [30] } \\
\text { Abdel-Monem et al. [31] }\end{array}$ & $x$ \\
\hline \multirow[t]{2}{*}{ Technological (TE) } & Time of Allocation (TE1) & & $x$ \\
\hline & Capacity of System integration (TE2) & Amy H.I.Lee et al. [17] & $x$ \\
\hline \multirow[t]{3}{*}{ Monetary (MO) } & Investment cost (MO1) & $\begin{array}{l}\text { Amy H.I.Lee et al. [17], } \\
\text { Nansheng Pang et al. [18], } \\
\text { A. Ayca Supciller et al. [30] }\end{array}$ & $x$ \\
\hline & Operation and Maintenance cost (MO2) & $\begin{array}{l}\text { Amy H.I.Lee et al. [17], } \\
\text { A. Ayca Supciller et al. [30] } \\
\text { Abdel-Monem et al. [31] }\end{array}$ & $x$ \\
\hline & Profit (MO3) & A. Ayca Supciller et al. [30], & $x$ \\
\hline
\end{tabular}




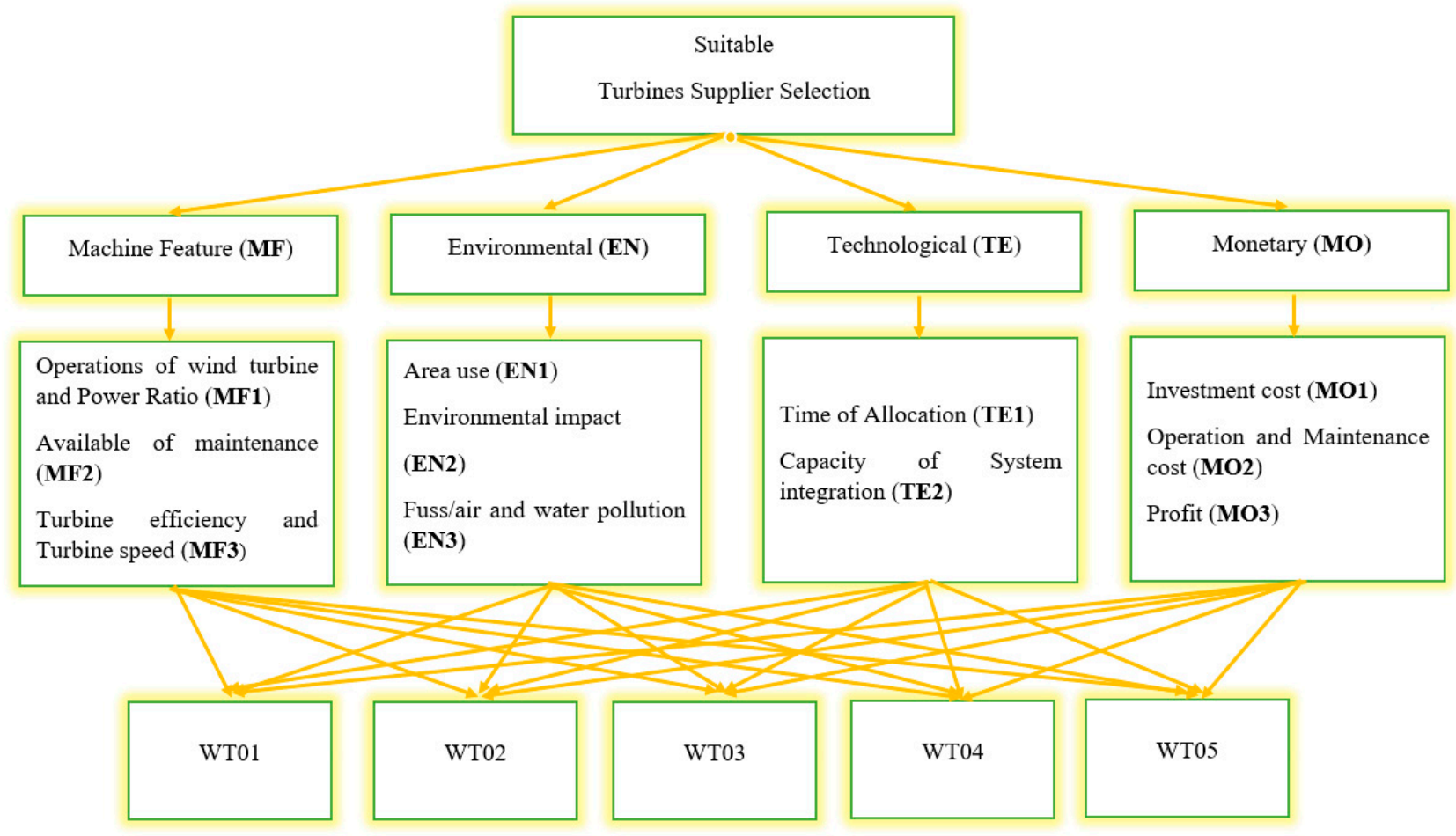

Figure 2. The structure between criteria, sub criteria and turbine suppliers.

In the second section of this research, SF-AHP is applied for calculating the weight of all criteria. Results from the SF-AHP model is shown in Table 3.

Table 3. Results from the SF-AHP model.

\begin{tabular}{ccccc}
\hline Criteria & SF Weights & Crisp Weights \\
\hline MF1 & 0.45787 & 0.50362 & 0.34068 & 0.07735 \\
MF2 & 0.39865 & 0.58105 & 0.29996 & 0.06742 \\
MF3 & 0.39710 & 0.56956 & 0.31904 & 0.06647 \\
EN1 & 0.45418 & 0.54697 & 0.27133 & 0.07908 \\
EN2 & 0.45272 & 0.53935 & 0.28534 & 0.07834 \\
EN3 & 0.48999 & 0.51121 & 0.27478 & 0.08589 \\
TE1 & 0.53767 & 0.47257 & 0.26500 & 0.09541 \\
TE2 & 0.60210 & 0.40643 & 0.25678 & 0.10810 \\
MO1 & 0.60043 & 0.39756 & 0.27625 & 0.10709 \\
MO2 & 0.64200 & 0.36365 & 0.25403 & 0.11587 \\
MO3 & 0.65927 & 0.33444 & 0.25955 & 0.11897 \\
\hline
\end{tabular}

In the next stage, these spherical fuzzy weights will be defuzzied into script weights using the average weight criteria of the WASPAS model for ranking wind turbines. The weighted normalized matrix and exponentially weighted matrix are shown in Tables 4 and 5 .

In this research, the authors proposed a hybrid model of the SF-AHP and WASPAS concepts to develop a decision support system in wind turbine supplier selection processes. A SF-AHP was applied to determine the weight of all criteria in the first stage, and the WASPAS model was then used for ranking all potential suppliers in the final stage. The aggregated utility function value $Q_{i}$ was calculated using weighted sum mode $Q_{i 1}$ (WSM) and weighted product model $Q_{12}$ (WSM), as can be seen in Table 6. From the results in Figure 3, the top three turbine suppliers were WT01, WT05, and WT04, with scores of $0.9233,0.8809$, and 0.8802 , respectively. Thus, supplier 01 (WT01) is the optimal supplier. 
Table 4. Weighted normalized matrix.

\begin{tabular}{cccccc}
\hline & WT01 & WT02 & WT03 & WT04 & WT05 \\
\hline MF1 & 0.06876 & 0.07735 & 0.06876 & 0.06016 & 0.06016 \\
MF2 & 0.05244 & 0.06742 & 0.05993 & 0.05993 & 0.06742 \\
MF3 & 0.05909 & 0.05170 & 0.06647 & 0.05909 & 0.04431 \\
EN1 & 0.06151 & 0.07908 & 0.07908 & 0.07030 & 0.06151 \\
EN2 & 0.07834 & 0.06093 & 0.05223 & 0.07834 & 0.06093 \\
EN3 & 0.08589 & 0.07515 & 0.07515 & 0.08589 & 0.08589 \\
TE1 & 0.09541 & 0.06361 & 0.07421 & 0.07421 & 0.09541 \\
TE2 & 0.08408 & 0.09609 & 0.09609 & 0.10810 & 0.10810 \\
MO1 & 0.10709 & 0.08329 & 0.07139 & 0.09519 & 0.07139 \\
MO2 & 0.11587 & 0.08690 & 0.10138 & 0.11587 & 0.11587 \\
MO3 & 0.11897 & 0.07932 & 0.09253 & 0.07932 & 0.11897 \\
\hline
\end{tabular}

Table 5. Exponentially weighted matrix.

\begin{tabular}{cccccc}
\hline & WT01 & WT02 & WT03 & WT04 & WT05 \\
\hline MF1 & 0.99093 & 1.00000 & 0.99093 & 0.98075 & 0.98075 \\
MF2 & 0.98320 & 1.00000 & 0.99209 & 0.99209 & 1.00000 \\
MF3 & 0.99220 & 0.98343 & 1.00000 & 0.99220 & 0.97341 \\
EN1 & 0.98032 & 1.00000 & 1.00000 & 0.99073 & 0.98032 \\
EN2 & 1.00000 & 0.98050 & 0.96873 & 1.00000 & 0.98050 \\
EN3 & 1.00000 & 0.98860 & 0.98860 & 1.00000 & 1.00000 \\
TE1 & 1.00000 & 0.96205 & 0.97631 & 0.97631 & 1.00000 \\
TE2 & 0.97320 & 0.98735 & 0.98735 & 1.00000 & 1.00000 \\
MO1 & 1.00000 & 0.97345 & 0.95751 & 0.98747 & 0.95751 \\
MO2 & 1.00000 & 0.96722 & 0.98465 & 1.00000 & 1.00000 \\
MO3 & 1.00000 & 0.95291 & 0.97054 & 0.95291 & 1.00000 \\
\hline
\end{tabular}

Table 6. Final value from WASPAS.

\begin{tabular}{cccc}
\hline Options & $Q_{i 1}$ & $Q_{i 2}$ & $Q_{i}$ \\
\hline WT01 & 0.9274 & 0.9223 & 0.9233 \\
WT02 & 0.8208 & 0.8124 & 0.8141 \\
WT03 & 0.8372 & 0.8304 & 0.8318 \\
WT04 & 0.8864 & 0.8787 & 0.8802 \\
WT05 & 0.8900 & 0.8786 & 0.8809 \\
\hline
\end{tabular}

It is shown that, besides Equation (17) being the general method for the results of the coefficient $\lambda$, a fixed value in the range of $0.1,0.2,0.3, \ldots, 1.0$ can be used. Therefore, in the first part of the sensitivity analysis, a modification in the coefficient $\lambda$ was conducted. The ranking performance of WASPAS for varying $\lambda$ values is exhibited in Table 7 .

Table 7. Rankings of robots for varying $\lambda$ values.

\begin{tabular}{lcccccccccc}
\hline & $\boldsymbol{\lambda}=\mathbf{0 . 1}$ & $\boldsymbol{\lambda}=\mathbf{0 . 2}$ & $\boldsymbol{\lambda}=\mathbf{0 . 3}$ & $\boldsymbol{\lambda}=\mathbf{0 . 4}$ & $\boldsymbol{\lambda}=\mathbf{0 . 5}$ & $\boldsymbol{\lambda}=\mathbf{0 . 6}$ & $\boldsymbol{\lambda}=\mathbf{0 . 7}$ & $\boldsymbol{\lambda}=\mathbf{0 . 8}$ & $\boldsymbol{\lambda}=\mathbf{0 . 9}$ & $\boldsymbol{\lambda}=\mathbf{1}$ \\
\hline WT01 & 0.8687 & 0.8694 & 0.8700 & 0.8707 & 0.8713 & 0.8720 & 0.8726 & 0.8733 & 0.8739 & 0.8746 \\
WT02 & 0.8221 & 0.8230 & 0.8239 & 0.8247 & 0.8256 & 0.8265 & 0.8274 & 0.8282 & 0.8291 & 0.8300 \\
WT03 & 0.8365 & 0.8373 & 0.8380 & 0.8388 & 0.8396 & 0.8404 & 0.8411 & 0.8419 & 0.8427 & 0.8434 \\
WT04 & 0.8836 & 0.8841 & 0.8846 & 0.8851 & 0.8856 & 0.8861 & 0.8865 & 0.8870 & 0.8875 & 0.8880 \\
WT05 & 0.8367 & 0.8376 & 0.8385 & 0.8394 & 0.8403 & 0.8412 & 0.8421 & 0.8430 & 0.8439 & 0.8447 \\
\hline
\end{tabular}




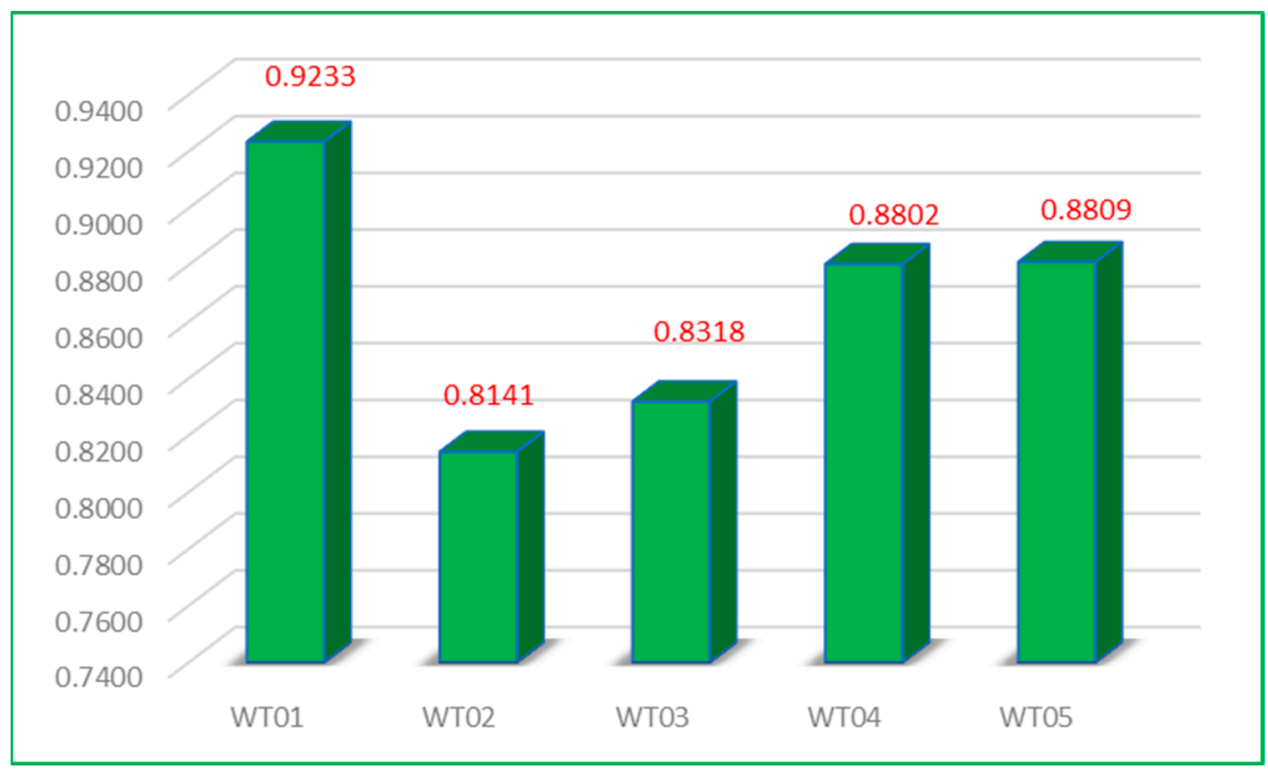

Figure 3. Potential suppliers ranking using the WASPAS model.

Table 6 shows the relative calculated values of the options according to the value of the coefficient $\lambda$. Note that the values of the coefficient $\lambda$ do not affect the change in the rank of the alternative. This research has led to the successful creation of a hybrid MCDM model, using SF-ANP and WASPAS, to determine the supplier evaluation and selection procedure in renewable energy projects.

\section{Conclusions}

According to the Global Wind Atlas, it is estimated that more than 39\% of Vietnam's waters and $8 \%$ of its land area has an average annual wind speed of over $6 \mathrm{~m} / \mathrm{s}$ at an altitude of $65 \mathrm{~m}$ [32]. The south has an average annual wind speed of over $7 \mathrm{~m} / \mathrm{s}$. This corresponds to wind resource potentials of $512 \mathrm{GW}$ and $110 \mathrm{GW}$. The technical potential of onshore wind power is about $42 \mathrm{GW}$, which is suitable for large-scale wind power projects [29].

This research proposed a novel MCDM model based on spherical fuzzy sets for wind turbine supplier selection in wind power energy projects. The suggested fuzzy MCDM method combines SF-AHP and WASPAS models to rank turbine suppliers for wind power projects. SF-FAHP is used to calculate the weight of criteria. WASPAS uses these obtained values to rank the turbine suppliers. Based on experts' opinions and the literature, a set of criteria for evaluating turbine suppliers has been considered, including machine features and environmental, technological, and monetary factors. The findings suggest that supplier WT01 is the most suitable. The most significant contributions and successes in this study can be described as follows:

$>\quad$ The proposed model is the first turbine evaluation and selection model in the wind power energy project in Vietnam using expert interviews and literature reviews.

$>$ Second, this is the first study to provide a case study on evaluating suppliers for the renewable energy sector that utilizes a combination of SF-AHP and WASPAS models.

$>\quad$ The results of this study can be a valuable guide in assessing and selecting equipment suppliers, not only for wind power energy projects but also for decision makers and investors in other renewable energy projects.

For further research on this topic, the study may be expanded to other MCDM approaches such as TOPSIS, data envelopment analysis (DEA), the Combined Comprise Solution (CoCoSo) method, etc. 


\begin{abstract}
Author Contributions: Conceptualization, V.T.N., N.H.H. and N.T.K.L.; Data curation, V.T.N., N.H.H. and N.T.K.L.; Formal analysis, V.T.N., N.H.H. and N.T.K.L.; Funding acquisition, V.T.N. and N.H.H.; Investigation, N.H.H. and N.T.K.L.; Methodology, V.T.N. and N.T.K.L.; Project administration, V.T.N.; Resources, N.H.H. and N.T.K.L.; Supervision, V.T.N.; Validation, N.H.H.; Writing-original draft, V.T.N. and N.H.H.; Writing-review and editing, N.T.K.L. All authors have read and agreed to the published version of the manuscript.
\end{abstract}

Funding: This research was funded by Van Lang University and The APC was funded by Van Lang University.

Acknowledgments: The authors wish to express their gratitude to Van Lang University, Vietnam for financial support for this research.

Conflicts of Interest: The authors declare no conflict of interest.

\title{
References
}

1. Cơ Hội để Việt Nam Triển Khai điện Gió Ngoài Khơi. Available online: https://moit.gov.vn/phat-trien-ben-vung/co-hoi-deviet-nam-trien-khai-dien-gio-ngoai-khoi.html (accessed on 17 September 2021).

2. Năng Hội để Việt Nam Triển Khai điện Gió Ngoài Khơi? Available online: https:/ / kienthuctonghop.vn/nang-luong-gio-la-gi (accessed on 17 September 2021).

3. Tìm Hiểu Về Năng Lượng điện Gió. Available online: https:/ / khangducconst.com/knowledge-base/tim-hieu-ve-nang-luongdien-gio/ (accessed on 17 September 2021).

4. The Comparison of Horizontal and Vertical Axis Wind Turbines. Available online: https://www.conserve-energy-future.com/ comparison-of-horizontal-and-vertical-axis-wind-turbines.php\#: \{\}:text=Wind\%20turbines\%20vary\%20in \%20size, axis $\% 20$ facing $\% 20$ the $\% 20$ wind $\% 20$ vertically (accessed on 17 September 2021).

5. What is MCDM/MCDA Model? Available online: https://www.1000minds.com/decision-making/what-is-mcdm-mcda\#: $\sim\{\}:$ text=Multi\%2DCriteria\%20Decision\%2DMaking\%20(,between\%20the\%20options\%20being\%20evaluated (accessed on 17 September 2021).

6. Mosadeghi, R. A Spatial Multi-Criteria Decision Making Model for Coastal Land Use Planning. Ph.D. Thesis, Griffith University, Brisbane, Australia, 2013.

7. Lee, H.C.; Chang, C.T. Comparative analysis of MCDM methods for ranking renewable energy sources in Taiwan. Renew. Sustain. Energy Rev. 2018, 92, 883-896. [CrossRef]

8. Kumar, A.; Sah, B.; Singh, A.R.; Deng, Y.; He, X.; Kumar, P.; Bansal, R.C. A review of multi criteria decision making (MCDM) towards sustainable renewable energy development. Renew. Sustain. Energy Rev. 2017, 69, 596-609. [CrossRef]

9. Çolak, M.; Kaya, İ. Prioritization of renewable energy options by using an integrated fuzzy MCDM model: A real case application for Turkey. Renew. Sustain. Energy Rev. 2017, 80, 840-853. [CrossRef]

10. Sadeghi, A.; Larimian, T.; Molabashi, A. Evaluation of renewable energy sources for generating electricity in province of Yazd: A fuzzy MCDM approach. Procedia-Soc. Behav. Sci. 2012, 62, 1095-1099. [CrossRef]

11. Wang, T.C.; Tsai, S.Y. Solar panel supplier selection for the photovoltaic system design by using fuzzy multi-criteria decision making (MCDM) approaches. Energies 2018, 11, 1989. [CrossRef]

12. Ishfaq, S.; Ali, S.; Ali, Y. Selection of optimum renewable energy source for energy sector in Pakistan by using MCDM approach. Process Integr. Optim. Sustain. 2018, 2, 61-71. [CrossRef]

13. Büyüközkan, G.; Karabulut, Y.; Güler, M. Strategic renewable energy source selection for turkey with hesitant fuzzy MCDM method. In Energy Management-Collective and Computational Intelligence with Theory and Applications; Springer: Cham, Switzerland, 2018; pp. 229-250.

14. Saraswat, S.K.; Digalwar, A.K.; Yadav, S.S.; Kumar, G. MCDM and GIS based modelling technique for assessment of solar and wind farm locations in India. Renew. Energy 2021, 169, 865-884. [CrossRef]

15. $\mathrm{Wu}, \mathrm{Y}$; $\mathrm{Xu}, \mathrm{C}$; Zhang, T. Evaluation of renewable power sources using a fuzzy MCDM based on cumulative prospect theory: A case in China. Energy 2018, 147, 1227-1239. [CrossRef]

16. Ramezanzade, M.; Karimi, H.; Almutairi, K.; Xuan, H.A.; Saebi, J.; Mostafaeipour, A.; Techato, K. Implementing MCDM Techniques for Ranking Renewable Energy Projects under Fuzzy Environment: A Case Study. Sustainability 2021, $13,12858$. [CrossRef]

17. Lee, A.H.; Hung, M.C.; Kang, H.Y.; Pearn, W.L. A wind turbine evaluation model under a multi-criteria decision making environment. Energy Convers. Manag. 2012, 64, 289-300. [CrossRef]

18. Pang, N.; Nan, M.; Meng, Q.; Zhao, S. Selection of Wind Turbine Based on Fuzzy Analytic Network Process: A Case Study in China. Sustainability 2021, 13, 1792. [CrossRef]

19. Shao, M.; Han, Z.; Sun, J.; Xiao, C.; Zhang, S.; Zhao, Y. A review of multi-criteria decision making applications for renewable energy site selection. Renew. Energy 2020, 157, 377-403. [CrossRef]

20. Kutlu Gündoğdu, F.; Kahraman, C. Spherical Fuzzy Sets and Spherical Fuzzy TOPSIS Method. J. Intell. Fuzzy Syst. 2019, 36, 337-352. [CrossRef] 
21. Montoya, F.G.; Manzano-Agugliaro, F.; López-Márquez, S.; Hernández-Escobedo, Q.; Gil, C. Wind turbine selection for wind farm layout using multi-objective evolutionary algorithms. Expert Syst. Appl. 2014, 41, 6585-6595. [CrossRef]

22. Yager, R.R. Pythagorean fuzzy subsets. In Proceedings of the 2013 Joint IFSA World Congress and NAFIPS Annual Meeting (IFSA/NAFIPS), Edmonton, AB, Canada, 24-28 June 2013; pp. 57-61.

23. Smarandache, F. A Unifying Field in Logics Neutrosophy: Neutrosophic Probability, Set and Logic; American Research Press: Rehoboth, DE, USA, 1999; pp. 1-141.

24. Kutlu Gündoğdu, F.; Kahraman, C. A Novel Spherical Fuzzy Analytic Hierarchy Process and Its Renewable Energy Application. Soft Comput. 2019, 24, 4607-4621. [CrossRef]

25. Kusumadewi, S.; Hartati, S.; Harjoko, A.; Wardoyo, R. Fuzzy Multi-Attribute Decision Making (Fuzzy MADM). J. Transform. 2006, $14,78-79$.

26. Singh, R.K.; Modgil, S. Supplier selection using SWARA and WASPAS-A case study of Indian cement industry. Meas. Bus. Excell. 2020, 24, 243-265. [CrossRef]

27. Mousavi-Nasab, S.H.; Sotoudeh-Anvari, A. An extension of best-worst method with D numbers: Application in evaluation of renewable energy resources. Sustain. Energy Technol. Assess. 2020, 40, 100771. [CrossRef]

28. Phát Triển điện Gió ở khu Vực Đồng Bằng Sông Cửu Long. Available online: https://dangcongsan.vn/kinh-te/phat-trien-diengio-o-khu-vuc-dong-bang-song-cuu-long-533961.html (accessed on 17 September 2021).

29. Đánh Giá Tình Hình Phát Triển Điện Gió ở Việt Nam. Available online: https://nangluongvietnam.vn/danh-gia-tinh-hinh-phattrien-dien-gio-o-viet-nam-27091.html\#: \{\}:text=Theo\%20B\%E1\%BA\%A3n\%20\%C4\%91\%E1\%BB\%93\%20Gi\%C3\%B3\%20To\% C3\%A0n,n\%C4\%83m\%20tr\%C3\%AAn\%207\%20m\%2Fs (accessed on 17 September 2021).

30. Supciller, A.A.; Toprak, F. Selection of wind turbines with multi-criteria decision making techniques involving neutrosophic numbers: A case from Turkey. Energy 2020, 207, 118237. [CrossRef]

31. Abdel-Monem, A.; Gawad, A.A. A hybrid Model Using MCDM Methods and Bipolar Neutrosophic Sets for Select Optimal Wind Turbine: Case Study in Egypt. Neutrosophic Sets Syst. 2021, 42, 1.

32. Wind Map. Available online: https: / www.windy.com/?7.319,57.217,3 (accessed on 17 September 2021). 